\title{
Article
}

\section{"Catching your tail and firefighting": The impact of staffing levels on restraint minimization efforts}

Mckeown, Michael, Thomson, Gillian, Scholes, Amy, Jones, Fiona, Baker, John, Downe, Soo, Price, Owen, Greenwood, Paul, Whittington, Richard and Duxbury, Joy

Available at http://clok.uclan.ac.uk/28607/

Mckeown, Michael ORCID: 0000-0003-0235-1923, Thomson, Gillian ORCID: 0000-0003-3392-8182, Scholes, Amy, Jones, Fiona, Baker, John, Downe, Soo ORCID: 0000-0003-2848-2550, Price, Owen, Greenwood, Paul, Whittington, Richard et al (2019) "Catching your tail and firefighting": The impact of staffing levels on restraint minimization efforts. Journal of Psychiatric and Mental Health Nursing, 26 (5-6). pp. 131-141. ISSN 1351-0126

It is advisable to refer to the publisher's version if you intend to cite from the work. http://dx.doi.org/10.1111/jpm.12532

For more information about UCLan's research in this area go to http://www.uclan.ac.uk/researchgroups/ and search for <name of research Group>.

For information about Research generally at UCLan please go to http://www.uclan.ac.uk/research/

All outputs in CLoK are protected by Intellectual Property Rights law, including Copyright law. Copyright, IPR and Moral Rights for the works on this site are retained by the individual authors and/or other copyright owners. Terms and conditions for use of this material are defined in the policies page.

\section{CLoK}

Central Lancashire online Knowledge www.clok.uclan.ac.uk

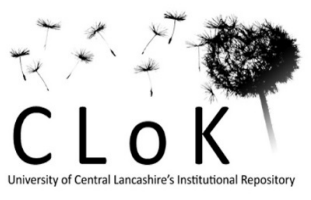




\section{'Catching your tail and firefighting': the impact of staffing levels on restraint minimisation efforts.}

Pre-publication Manuscript - Accepted for publication Journal of Psychiatric and Mental Health Nursing.

Mick McKeown, Gill Thomson, Amy Scholes, Fiona Jones, John Baker, Soo Downe, Owen Price, Paul Greenwood, Richard Whittington \& Joy Duxbury

\section{Accessible Summary}

\section{What is known on the subject?}

- Mental health nursing in the UK and other countries faces an acute workforce crisis.

- Safe staffing levels are called for, and in some jurisdictions have been legislated for.

- The evidence base linking staffing levels and patient outcomes is limited.

- Staffing levels are implicated in adverse experiences of service users and staff within mental health ward settings, and they might contribute to levels of violence and aggression and the application of restrictive practices, such as physical restraint but there is limited research evidence to support this.

- Programmes such as Safewards, No Force First, the Engagement Model and the Six Core Strategies can reduce the use of restrictive practices.

\section{What does this paper add to existing knowledge?}

- Staffing levels on acute mental health wards appeared crucial in the implementation of a restraint minimisation project.

- Both staff and services users implicate insufficient staffing for deficiencies in the relational elements of care, such as lack of face to face contact between nurses and service users. 
- Similarly, staffing levels are associated with perceived problems in the cause of violence and aggression and responses to it.

- Despite successes in minimising restrictive practices in this project, difficulties implementing alternative forms of practice that would reduce use of physical restraint, such as de-escalation, were also attributed to staffing levels.

- There is an irony that a project concerned with safety itself provoked concern over safe staffing levels.

\section{Abstract}

Introduction: Safe staffing and coercive practices are of pressing concern for mental health services. These are inter-dependent and the relationship is under-researched.

Aim: To explore views on staffing levels in context of attempting to minimise physical restraint practices on mental health wards. Findings emerged from a wider dataset with the broader aim of exploring experiences of a restraint reduction initiative.

Methods: Thematic analysis of semi-structured interviews with staff $(n=130)$ and service users $(n=32)$.

Results: Five themes were identified regarding how staffing levels impact experiences and complicate efforts to minimise physical restraint. We titled the themes - 'insufficient staff to do the job'; 'detriment to staff and service users'; 'a paperwork exercise: the burden of nonclinical tasks'; 'false economies'; and, 'you can't do these interventions'.

Discussion: Tendencies detracting from relational aspects of care are not independent of insufficiencies in staffing. The relational, communicative, and organisational developments that would enable reductions in use of restraint are labour intensive and vulnerable to derailment by insufficient and poorly skilled staff. 
Implications for Practice: Restrictive practices are unlikely to be minimised unless wards are adequately staffed. Inadequate staffing is not independent of restrictive practices and reduces access to alternative interventions for reducing individuals' distress.

Keywords: acute care, staffing/resources, physical restraint, qualitative methodology

Relevance: This paper is relevant to mental health nursing because it deals with nurses' and service users' views on nurse staffing levels, which is an under researched and highly topical contemporary issue. 


\section{Introduction}

Coercion has been shown to be harmful for both service users and staff within mental health care; being injurious, traumatising and re-traumatising, making the case for trauma-informed care (Department of Health 2014, Duxbury et al. 2011, MIND 2013, Muir-Cochrane 2018, Sweeney et al. 2018). Concomitantly, there has been widespread international interest in nurse staffing levels, across health care contexts, including mental health. Commentary, research and policy debates invariably refer to notions of 'safe staffing'; implicitly acknowledging denuded staffing levels undermine safety of service users and staff alike (Baker et al. 2016, Jones \& Gregory 2017, Littlejohns 2015, Riahi et al. 2016). Governance systems have, with variable success, sought evidence to support calculation of safe staffing (Griffiths et al. 2016, Health Foundation 2017).

\section{Project Context}

This paper reflects upon key findings from a large scale study of the REsTRAIN Yourself (RYS) initiative, concerned with the minimisation of physical restraint. The RYS project aimed to implement and evaluate a UK adaptation of the 6 Core Strategies (C) (6CS) approach to minimising restrictive practices (Huckshorn 2006). The overall mixed-methods study compared usage of physical restraint across 14 acute mental health wards, where 7 wards initially received the RYS intervention. The intervention comprised 4 months of intensively facilitated work with whole teams directly in the ward setting, with some off-ward input. RYS aimed to support the implementation of: team goals for reducing restraint; meaningful reflection on restraint usage; improved understanding of aggression; a partnership approach to restraint minimisation; environmental and procedural modifications; and effective debriefing. 
The project achieved substantial reductions in use of physical restraint (Duxbury et al. 2019a), in line with other evaluations of the 6CS (Barton et al. 2009, Guzman-Parra at al 2016, LeBel, 2011, Lewis et al 2009, Putkonen et al 2013). Evaluation also included qualitative interviews with staff and patients concerned with overall experiences of participating in the project and experiences of restraint practices, as well as ethnographic observations of ward cultures and practices (see Duxbury et al. 2019b). We report here on a distinct sub-set of the qualitative data with a specific focus on the perceived influence and importance of staffing levels. These findings are not included in other published papers from the study as we felt they were of sufficient importance to merit presentation in their own right. Our reasoning in this regard included consideration of staffing levels as a topical focus for international concern and the fact that nurses and other mental health care practitioners are open to criticism over the coercive character of services, and reflecting on staffing issues is an important element of addressing such critique.

\section{Background}

Study of acute mental health wards has demonstrated the value of adequate complements of registered nursing staff in enhancing overall quality of care and, particularly, reducing levels of coercion (Bowers et al, 2007). Baker and Pryjmachuk (2016) reinforce the links between concerns for safety and appropriate staffing levels. They point out the origin of the most recent government interest in safe staffing levels stemming from the Francis Inquiry (2013) into catastrophic service failings. However, the UK evidence review for safe staffing, initiated by the National Institute of Health and Clinical Excellence (NICE) was halted before mental health nursing had been considered.

Internationally, jurisdictions such as California (Spetz 2004) and Victoria in Australia (Gerdtz \& Nelson 2007) have legislated for safe staffing levels, yet such ground-breaking legal 
developments have not necessarily extended to mental health services. Globally, trade unions have argued for safe staffing, claiming it as an important employment relations issue affecting the prevalence of violence and restrictive practices (see di Martino 2003, International Council of Nurses 2014, International Labour Organization 2005, RCN 2014, 2018; Unison 2017, 2019).

Despite substantial professional, policy and legislative interest in safe staffing levels, there is no research in a mental health context directly exploring views of stakeholders on the subject. Nor is there research into the interaction between staffing levels and attempts to minimise restrictive practices. Inquiry into staff experiences, however, highlights the significant contribution of inadequate staffing levels and work casualization amongst other resource pressures to occupational stress, dissatisfaction and burnout (Jenkins \& Elliot 2004, O'Connor et al. 2018, Taylor \& Barling 2004), associated with adverse impact upon patient experience (Kieft et al. 2014). More general studies of mental health ward environments also remark upon negative effects of insufficient staffing for service users and damaged therapeutic relations (Cleary 2004, Gilburt et al 2008, Quirk \& Lelliot 2001). Moreover, patients report concerns for the welfare of staff having to cope with challenges of ward care and insufficient staffing (Mistry et al. 2015). These and other studies highlight limited time spent with service users because of administrative pressures, causing staff stress and service user dissatisfaction (Reid et al. 1999, Sharac et al. 2010). Other UK evaluations of initiatives to minimise restrictive practices may not explicitly refer to inadequate staffing levels, but do cite additional demands of complex change processes on top of the usual demanding nature of ward care as complicating factors (Bowers et al. 2015). A Europe-wide Delphi study identified the influence of staff and environment on levels of violence as a priority research area for future study of coercive practices and their reduction (Cowman et al. 2017). 


\section{METHODS}

Staff and service user views on the interaction between coercive practices and safe staffing levels have not hitherto been investigated directly. In the context of a wider project to minimise use of physical restraint on acute mental health wards, we aimed to explore the views of staff and services users surrounding staffing levels, and perceived interaction with patient care and the occurrence and management of violence and aggression. The qualitative analysis presented is a sub-set from a wider analysis with the broader aim of exploring participant experiences of the restraint reduction initiative. The research took place on 14 acute mental health wards; two from each of the seven NHS Trusts across the North West of England. Half of the wards, one in each Trust, received the RYS intervention. Data collection took place between July 2014 - February 2016.

\section{Research team and reflexivity}

Data collection was undertaken by four members of the team; two research assistants (one with a psychology background and one with lived experience of using inpatient mental health services, and two academic researchers (one previously a mental health nurse, one without

a clinical background). The broader team, variously involved in analysis, comprised academic researchers from mental health nursing, health and social science disciplines. The range of perspectives and experiences of the research team helped to facilitate access to service user and staff participants and allowed for a thoughtfully reflexive engagement with the data. A collective approach enabled the team to capitalise upon shared identities in encouraging participation but set aside any preconceived positioning to the participants and data for purposes of analysis. 
Semi-structured, audio-taped interviews were undertaken with staff $(n=130)$ and service users ( $n=32)$. Interviews followed a topic guide that addressed participant experiences and views on: violence and aggression in the ward context; nursing care and staffing levels; and restrictive practices and approaches to reduce these. Participants on intervention wards were specifically asked about experiences of the RYS project.

\section{Analysis}

Interviews were digitally recorded and transcribed verbatim. MAXQDA (version 11) software was used to support thematic analysis (Braun \& Clark 2005) guided by a critical realist theoretical standpoint, which combines appreciation of the importance of individual agency and subjectivity but also considers the power of structural forces to shape and influence individual behaviour and responses (McEvoy \& Richards 2003). Initially, two researchers [GT, AS] independently coded a sample of interview transcripts and discussed analytic decisions to create a coding frame. Subsequently, data was coded using the agreed framework, with any revisions discussed on an ongoing basis. Other team members [MM, FJ] involved in the data collection also contributed to and confirmed the identified themes. The qualitative analysis of the evaluation of the RYS intervention collected on the 7 intervention wards, post-intervention, is presented in a companion article (Duxbury et al. 2019b). Analysis relating specifically to staffing levels is uniquely presented in this paper.

\section{Ethics}

The study was funded by the Health Foundation and conducted ethically, receiving ethical approval via the Health Research Authority (ref. 14/YH/0164).

\section{FINDINGS}


162 participants included 130 staff (82 pre-intervention, 48 post-intervention) and 32 service users (25 pre-intervention, 7 post-intervention). The staff included a mixture of gender, grades, and day and night workers; the majority comprising mental health nurses. Service users reflected the demographic profile of the participating wards (see Table 1.).

[insert Table 1 about here]

Five broad themes were identified which we describe below and illustrate with selected quotes from participating staff and service users. These themes articulate staff and service users' views and experiences that consider the impact of staffing levels with particular relevance to the incidence of conflict, responses to this, and attempts at minimising restrictive practices in the ward context.

\section{Insufficient staff to do the job}

Lack of appropriately trained staff, compounded by increasing patient acuity and burden of non-clinical tasks, created a vicious circle in terms of contributing to, and subsequent management of violence/aggression, including restraint use. Health professionals consistently reported working in environments with poor staffing levels, adversely impacting quality of care and causing reactive practices.

This resulted in staff:

'feeling like you're catching your tail a lot of the time and firefighting'. (Site 5_Staff 5_T1)

Teams appeared to service users to lack sufficient staff to attend to their needs: 
The staff are doing two, three people's jobs and trying to listen to the patients, it's not enough. (Site 7_Service user 3_T1)

Insufficient staffing was directly implicated in the causal development of violent incidents requiring use of restraint:

If you've ended up in a restraint situation, it's usually on a day where you are short staffed or things have gone on ... or it is very busy and it's very hectic. And that probably tells you something about, you know, why it's happened in the first place. (Site 4_Control_Staff 5_T1)

It was not unusual for concerns to be expressed in terms of teams being stretched beyond safe levels of responsiveness to needs or risk:

And it's like staffing levels and ... regarding the patient care being compromised. Because I came on shift, there was, there was myself, I'm newly qualified, there was another nurse and a support worker, and we had two one to ones, we should have had five staff. The ward was escalating ... I was supervising, someone returned back from AWOL [absent without leave], I was on a one to one with someone who was in the dorm, I was doing the garden safety check, so going round checking everyone. It's like you do find yourself doing five jobs at the same time. (Site 7_Intervention_Staff 2_T2) 
On only a small number of occasions did staff feel they had 'safe staffing levels' to deal with events and adequately respond to the 'ticking over' of acute psychiatric inpatient environments. Benefits for staff, patients and the ward climate were clearly evident:

The Trust have actually been very good around how we staff the ward. I've increased our Band 3 staffing because we haven't got enough regular Band 5s, so that I always have more people on the ward, or trying to always have a number of people on the ward that know the ward and know the patients, to try and provide some consistency. (Site 4_Intervention_Staff 1_T2)

Staff further acknowledged the value of informal peer support amongst patients, and how this may substitute for time spent with professionals:

Because of the staffing levels, sometimes we can't be there, there and then for that patient, as much as we can, unless, because sometimes, the quiet ones, can go amiss sometimes. And when, it's nice to see other patients helping other patients with needs. (Site 6_Intervention_Staff 17_T2)

\section{Detriment to staff and service users}

Denuded staffing levels were implicated in harmful outcomes for both service users and staff in the context of preventing or managing violence and aggression. Several staff members referred to how low staffing contributed to detrimental outcomes when conflict occurred.

In this case, remarking on physical injury and wellbeing: 
Two staff on here were seriously injured and the patient summoned help because there was no staff around ... three staff are still off sick because they were traumatised by it, it was a serious, serious assault. And it makes you wonder, had there been more staff (Site 3_Intervention_Staff 4)

And, here, emphasising psychological distress:

I've left one particular job, and l've been doing this job twenty four years and I have seen lots and lots and lots of things, I left crying. And it takes a lot to make me cry. (Site 3_Intervention_Staff 9_T1)

Inadequate staffing levels were seen to be antithetical to supportive relationships and therapeutic alliance in particular:

There's not enough staff. And it's got loads worse since [the cuts started]. The staff are doing two/three people's jobs and trying to listen to the patients, it's not enough. (Site 7_Intervention_Service User 3)

Staff reflected that the absence of personnel to deal communicatively with service user distress could translate into over-reliance upon pharmacology: 
I have found that l've used medication more. I think it is just because there isn't the staff ... So it is a case that if someone does kick off, we haven't got the staff to deal with it. (Site 3_Intervention_Staff 2_T2)

Staff identified a cyclical relationship between stress on staff and incidence of violence and aggression on the wards:

I think the other impact of reduced staffing, staff that are stressed for long periods because of the pressures on them, that in itself is a contributor to situations ... impacts on the quality of care, which in turn increases the level of frustration with patients. (Site 4_Control_Staff 3_T1)

And similar observations were made by service users:

You can sometimes feel the stress getting more and more ... worse when there's obviously less staff on, or people you don't know (Site 4_Control_Service user 2_T1).

\section{A paperwork exercise: the burden of non-clinical tasks}

There was a sense that non-clinical tasks diminished patient-staff contact, sustaining a demarcation of ward space between staff and service user areas. Administrative burdens diluted the visibility/availability of registered nurses in patient areas, meaning staff had limited opportunities to get to know patients and their histories, undermining positive relationships. This, in turn, limited early intervention efforts to defuse conflict-based 
situations by identifying and respond to cues, and generated disquiet over professional role and identity.

This nurse highlights how time spent away from patient care diminishes such aspects of selfimage:

I've found myself spending more time on a computer than I did when we had paper notes. So as well as doing the stuff that you've got to do for the ward this day, you've got stuff that's coming through [by email] that you're responsible for. I feel my role that I trained to do at times, it seems a far place from what I actually do. And for me, I struggle with that because I'm a clinical nurse and my practice is sat with my patients talking with them. (Site 4_Control_Staff 3_T1)

Limitations on time spent in face to face contact with service users also reflected staff seniority:

I'm a named nurse for two patients on the unit. But because of my job role as a staff nurse, they, the patients spend more time with the nursing assistants. Which can also be kind of a bone of contention, because l'm in charge of this person's care ... But actually, the amount of time I get to spend with the patient is practically zero on a bad day. I started my nurse training because I want to take care of people. And I feel that it's not the job I thought it would be, it's more of a paperwork exercise. (Site 2_Intervention_Staff 3_T2) 
In the extreme, one staff member reflected how her administrative workload meant that she only spent time with patients during a violent/aggressive incident:

I think there's so much demand, like paperwork and things that you don't have time to spend with patients. I do feel that the only time you do engage with someone is when they are kicking off or when people are restrained, to be honest. (Site 7_Intervention_Staff 2_T2)

Service users complained of a lack of staff presence:

You can be a long time on the ward without seeing staff ... or they have no time for you when they are doing other things. There aren't enough of them (Site 2_Intervention_Service user 3_T1)

In this case, linking dissatisfaction to the perception that staff separate themselves from service users within the ward space:

They should be then helping the patients. Not thinking, oh god, I didn't like that, I'm going to lock myself in the office and have a cup of tea. No, instead of locking themselves away, they should be more proactive. (Site 5_Intervention_Service user 1_T1)

Paradoxically, new practices introduced by the RYS project were also reported to increase record keeping, diverting staff away from direct contact with service users, such as the newly 
introduced practice of recording all aggressive incidents on visually representative 'Safety Crosses':

I mean, to be honest, and it sounds awful ... but we're not going to be thinking how many times a patient tells us to bugger off or F-off or whatever and put a cross on it ... that's the least thing on our mind, is putting stuff on the wall, a tick or a cross. We'll think of the patients first. (Site 5_Intervention_Staff 1_T2)

\section{False economies}

The employment of temporary staff to fill roster shortfalls was considered a 'false economy' due to patterns of restricted engagement with patients and staff teams, perceived knowledge and skills shortcomings, and subsequently increased work pressure. Illogically, temporary personnel were often allocated lengthy stints of close observation of the most vulnerable or distressed individuals.

The use of ad-hoc staff created discontinuities of care and additional work for the permanent staff:

Well because we've got high acuity and our staff are off sick or whatever, through stress and different other things. So when you're getting the agency staff, they're not actually, you know, not that I'm saying they're not any good, but they don't know the patients, they don't have the same level of engagement. They just wait until the end of the shift until they can go home. They're not like kind of gelled in the team (Site 7_Intervention_Staff 3_T2) 
One individual reflected on the difficulties of implementing a cultural change (such as RYS) when the ward was heavily dependent on temporary staff, not aware of the harm minimisation approach and techniques:

I suppose there has been days when it's very difficult, yes, because you get a lot of bank staff on who only know the old way. And they probably think, what's going on here, they're all standing back doing nothing. So maybe sometimes the bank staff should be educated in it ... everyone needs showing the way. (Site 3_Intervention_Staff 4_T2)

\section{'You can't do these interventions'}

Despite successes in reducing use of physical restraint, low staffing levels were both a direct and indirect impediment to new tools, techniques and practice-based changes introduced as part of the RYS intervention.

For example, efforts to provide a greater visible nursing presence in all ward areas was frustrated by insufficient staff numbers:

The difficulty has been that with regards to qualified staff, we've been really down and we're on the risk register for that, and that probably hasn't helped things ... And that's a difficulty in itself, with regards to change. (Site 4_Intervention_Staff 1_T2) 
A combination of high patient acuity, in conjunction with low staffing levels, created a difficult climate on the wards and changes in practice were problematic, due to the demands on staff time:

I don't feel that actually there were that many techniques that have been implemented, to be quite honest with you, for various different reasons. I'm not sure that that's a fault of the project. I'm not really sure how much the staff have embraced it on the ward, given the fact that the ward's so acute and they've not had time to kind of absorb it. (Site 7_Intervention_Staff 3_T2)

Some nurses referred to occasions where there were not enough staff to proactively manage situations of violence and aggression, through greater use of de-escalation techniques for instance:

We teach de-escalation, and in an ideal world, all that would be absolutely perfect. And then you come to the wards and it just doesn't work like that. Because you're under so much pressure for other things, other jobs and other patients, that you can't sit there and talk to somebody for an hour, deescalate somebody. I wish I could but you can't. (Site 4_Control_Staff 4_T1)

Ward community meetings could be cancelled because of other priorities causing additional pressures on staffing, especially in circumstances where they were largely facilitated by one or two key individuals. Similarly, the valued practice of post-incident or post-restraint debriefing was less likely to occur due to insufficient staffing: 
I think if you speak to staff, l'm sure they'd say [debriefings] were really beneficial. And especially with regards to reflection and how nurses now have to revalidate and produce all these kind of documents ... it is the way forward. But I think that, somewhere, someone needs to realise that, actually, you can't do these interventions on a ward with five staff and twenty patients; twenty acutely unwell patients (Site 7_Intervention_Staff 3_T2)

When staffing levels were sufficient, this enabled more meaningful activities to be organised and staff to demonstrate their flexibility in meeting needs with virtuous effects on relationships and appreciation. This included possibilities for arranging excursions off the ward for some patients, and potential for more quality time to be spent with those remaining on the ward. The observable benefits of these activities for patients created a positive impetus for proactive staff engagement and for further activities to be organised: 'because they're [staff] seeing the outcomes of that, then they're doing it more'. Furthermore, the increase in these opportunities were considered invaluable for therapeutic engagement and relationship building:

We've built upon our activities hugely really and there's a couple of support workers are taking turns to plan those activities. And they're going round the patients at the time to say, what sort of things would you want to do? So the activities are changing all the time, it's not the same things over and over again. The walks have been really good and they're on every day anyway ... it's been giving the patients something else to do. (Site 5_Intervention_Staff 20_T2)

\section{Discussion}


The findings presented here add to the body of knowledge about staffing in acute mental health settings, reflecting disquiet amongst staff and service users with deleterious effects of low staffing levels. Importantly, in order for interventions that reduce restrictive practices to be successfully implemented staffing needs consideration. Participants in the RYS project identified staffing levels as a significant factor in the prevailing ward emotional climate and the capacity of teams to act progressively in preventing or managing violence and aggression. In a vicious circle, attempts at initiating changes to practice in this regard were themselves vulnerable to negative impacts of insufficient staffing, even within a project such as ours which involved substantial input and support at ward level and was ultimately successful in reducing usage of physical restraint (Duxbury et al. 2019a). Thus, systematic approaches to minimising restrictive practices such as de-escalation, debriefing, improving visibility and availability of staff in ward areas, community meetings, and modifying records to better monitor violence and aggression, were all at the mercy of denuded staffing numbers and ultimately more difficult to enact. In such unpropitious circumstances, the resilience of staff committed to more therapeutic environments and able to enact change characterised by relational rather than restrictive ideals was commendable.

Aguilera-Serrano and colleagues (2018) emphasise the value of human relational approaches to seeking out and acting upon service user and carer views, and ensuring their input into decision making, as means for reducing coercive measures. Efforts to bring about more effective communication of individuals' wishes and their ideas for alternatives to coercion greatly increase potential for collaborative staff-patient alliances and reduced conflict (Looi et al. 2015, Masters 2018). All of the published systematic approaches to minimising coercive practices, such as Safewards (Bowers et al. 2015), No Force First (Ashcraft \& Anthony 2008), the Engagement Model (Borckardt et al. 2011) and the Six Core Strategies (Huckshorn 2006), have an emphasis upon relational and communicative aspects of care. This chimes in with policy and practice support for an ethos of co-production (Fisher 
2016), arguably supporting broader shifts towards democratised relations of care (McKeown et al. 2018). Critics call attention to epistemic and cultural barriers to the realisation of such desirable goals (Liegghio 2014), and nursing's complicity within cycles of violence (Gadsby 2018, McKeown et al. 2019). Notwithstanding such critique, an appreciably formidable stumbling block would appear to be prevailing vicissitudes of denuded staffing levels, which clearly obstruct teams' capacities to enact relational approaches to care. Further research needs to model optimum staffing ratios and skill mix to enable embedding of appropriate interventions.

It is often claimed that physical restraint is an intervention of last resort, yet proactive alternatives, such as de-escalation are arguably under-utilised (Pereira et al. 2006, Perkins et al. 2012), and this may not be independent of staffing levels (Price \& Baker 2012). Criticisms are often grounded in wider disquiet with prevailing levels of compulsion and coercion within modern mental health services (Szmukler \& Appelbaum 2008). Such research and commentary echoes our findings that staff felt remedial measures such as deescalation and post incident debriefings were challenging to implement due to insufficient staffing. The noted burden of record keeping, and how this serves to keep skilled staff away from service users is not a new observation. This has been subject to previous inquiry and critical commentary that challenges some of the absurdities of writing about people without them, or basing risk management upon absentee narratives (Coffey et al. 2017, McKeown et al. 2017). Our study adds an appreciation of how such tendencies towards privileging record keeping over direct care are bound up with staffing pressures and are inseparable from concerns regarding coercive practices and attempts to minimise them.

Overlain on this are professional crises of legitimacy (McKeown \& White 2015) fed by high profile service failings, and widespread clamour for blame and accountability (Roberts \& lon 
2014). Criticisms of nursing's contribution abound, undermining public image, morale and confidence to commit to change (ten Hoeve et al. 2014). Such a backdrop is discouarging for seeking collective solutions via dialogue, or a truly honest exchange of views (Randall \& McKeown 2014). A blame or scapegoating culture limits possibilities for people to own up to mistakes, even those made in good faith. With this in mind, progressive organisations have been urged to instigate no blame systems for responding to errors and service failings (Dekker 2012).

Arguably, the perfect storm of funding cuts, aging workforce, lack of attention to workforce planning, cessation of the nurse training bursary, ideologically informed antipathy to immigrant workers and Brexit implications for EU staff, have coalesced in a pressing NHS workforce crisis, now and for the future, particularly for mental health nursing (Imison 2016, National Audit Office 2016). Concern with safe staffing levels in mental health settings is not independent of other critique of ward care and levels of coercion (Baker et al. 2016, Jenkins \& Elliott 2004, Gilburt et al. 2008, Quirk \& Lelliott 2001). The causative factors of mental distress are complex but it is difficult not to take a view that the same economic inequalities squeezing the resources of welfare and healthcare are also implicated in increasing demand for mental health care (Macintyre et al. 2018, Stuckler et al. 2018). It is also apparent that mental health services take on an increasingly coercive character when such economic conditions prevail, with, for example, levels of compulsion in England having increased substantially year on year since the banking crisis of 2008 and subsequent austerity (Care Quality Commission 2017, Thomas 2016). Ironically, this timescale is more or less coterminous with the reform of English mental health legislation, ostensibly geared towards a more community care oriented system.

\section{Implications for Practice}


Efforts to reduce restrictive practices will be hampered unless wards have adequate staffing levels. Resistance to austerity policies coincides with calls for parity of esteem between mental health and other healthcare services, grounded in the plausible view that mental health services represent substantially more demand than reflected in resource allocation (Docherty \& Thornicroft 2015). Such concerns with overarching political economy and its impact upon the workforce and quality of care justify casting restrictive practices as an employment relations matter; legitimately within the purview of staff representative organisations (McKeown \& Foley 2015). Organisations and policy makers might then concentrate on environmental, contextual and resourcing factors, rather than identify problems exclusively in terms of perceived aberrant behaviour of staff or service users. This could include reference to staffing levels but also how these interact with matters of building design, morale, insecure and precarious work, associated uncertainty, and access to training.

\section{Conclusion}

Novel thinking about prevention and management of aggression and violence, such as exemplified by RYS, provides one set of answers for questions posed regarding deleterious effects of coercive practices. It is not without irony that a project concerned with safety was to some extent undermined by concerns over safe staffing levels. Central to various objections to perceived unsafe staffing is detriment to therapeutic relations, with ward spaces separated into staff and patient areas and denuded of face to face contact between the two. Democratised alternatives could provide remedies for an endemic alienation within services, offer more consensual, cooperative, peaceful environments, and minimise conflict between service users and staff for mutual benefit. RYS, amongst other initiatives, advocates participatory means for reflection and decision-making. To achieve systematic democratisation of care, safe staffing levels must be agreed and implemented. 


\section{References}

Aguilera-Serrano, C., Guzman-Parra, J., Garcia-Sanchez, J.A., Moreno-Küstner, B. and Mayoral-Cleries, F. (2018) Variables associated with the subjective experience of coercive measures in psychiatric inpatients: a systematic review. The Canadian Journal of Psychiatry, 63(2), 129-144.

Ashcraft, L. \& Anthony, W. (2008) Eliminating seclusion and restraint in recovery-oriented crisis services. Psychiatric Services, 59: 1198-1202.

Baker, J., Pryjmachuk, S. and Mental Health Nursing Academics UK (2016) Will safe staffing in Mental Health Nursing become a reality? Journal of Psychiatric and Mental Health Nursing, 23(2), 75-76.

Barton SA, Johnson MR, Price LV (2009) Achieving restraint-free on an inpatient behavioral health unit. Journal of Psychosocial Nursing and Mental Health Services, 47:34-40.

Borckardt, J.J., Madan, A., Grubaugh, A.L., Danielson, C.K., Pelic, C.G., Hardesty, S.J., Hanson, R., Herbert, J., Cooney, H., Benson, A. and Frueh, B.C. (2011) Systematic investigation of initiatives to reduce seclusion and restraint in a state psychiatric hospital. Psychiatric Services, 62(5), 477-483.

Bowers, L., Whittington, R., Nolan, P., Parkin, D., Curtis, S., Bhui, K., Hackney, D., Allan, T., Simpson, A. and Flood, C. (2007) The city 128 study of observation and outcomes on acute psychiatric wards. Report to the NHS SDO Programme. City University, London. 
Bowers, L., James, K., Quirk, A., Simpson, A., Stewart, D. and Hodsoll, J. (2015) Reducing conflict and containment rates on acute psychiatric wards: The Safewards cluster randomised controlled trial. International Journal of Nursing Studies, 52(9), 1412-1422.

Care Quality Commission (2017) Monitoring the Mental Health Act in 2016/17. CQC, Newcastle. https://www.cqc.org.uk/sites/default/files/20180227 mhareport web.pdf (accessed 8 September 2018).

Cleary, M. (2004) The realities of mental health nursing in acute inpatient environments. International Journal of Mental Health Nursing, 13(1), 53-60.

Coffey, M., Cohen, R., Faulkner, A., Hannigan, B., Simpson, A. and Barlow, S. (2017) Ordinary risks and accepted fictions: how contrasting and competing priorities work in risk assessment and mental health care planning. Health Expectations, 20(3), 471-483.

Cowman, S., Björkdahl, A., Clarke, E., Gethin, G. and Maguire, J. (2017) A descriptive survey study of violence management and priorities among psychiatric staff in mental health services, across seventeen European countries. BMC Health Services Research, 17(1), 59.

Department of Health (2014) Positive and proactive care: reducing the need for restrictive interventions. $\mathrm{DH}$, London. 
Dekker, S. (2012) Just culture: Balancing safety and accountability. $2^{\text {nd }}$ Edition. CRC Press, London.

di Martino, V. (2003) Relationship between work stress and workplace violence in health sector. International Labour Organisation, Geneva.

Docherty, M. \& Thornicroft, G. (2015) Specialist mental health services in England in 2014: overview of funding, access and levels of care. International Journal of Mental Health Systems, 9(34), doi.org/10.1186/s13033-015-0023-9

Duxbury, J., Aiken, F., \& Dale, C. (2011) Deaths in custody: the role of restraint. Journal of Learning Disabilities and Offending Behaviour, 2(4), 178-189.

Duxbury, J., Thomson, G., Scholes, A., Jones, F., Baker, J., Downe, S., Price, O., Greenwood, P., Whittington, R. \& McKeown, M. (2019b) Staff experiences and understandings of the REsTRAIN Yourself initiative to minimise the use of physical restraint on mental health wards. International Journal of Mental Health Nursing, doi.org/10.1111/inm.12577

Fisher, P.L. (2016) Co-production: what is it and where do we begin? Journal of Psychiatric and Mental Health Nursing, 23(6-7), 345-346.

Francis, R (2013) Report of the Mid Staffordshire NHS Foundation Trust Public Inquiry. The Stationary Office, London. 
Gadsby, J. (2018) Nursing violence, nursing violence. In P. Bull, J. Gadsby \& S. Williams (eds) Critical mental health nursing: observations from the inside. Ross-on-Wye: PCCS Books. pp. 13-29.

Gilburt, H., Rose, D. and Slade, M. (2008) The importance of relationships in mental health care: A qualitative study of service users' experiences of psychiatric hospital admission in the UK. BMC Health Services Research, 8(1), p.92.

Griffiths, P., Ball, J., Drennan, J., Dall'Ora, C., Jones, J., Maruotti, A., Pope, C., Saucedo, A.R. and Simon, M. (2016) Nurse staffing and patient outcomes: strengths and limitations of the evidence to inform policy and practice. A review and discussion paper based on evidence reviewed for the National Institute for Health and Care Excellence Safe Staffing guideline development. International Journal of Nursing Studies, 63, 213-225.

Guzman-Parra, J., Aguilera Serrano, C., García-Sánchez, J.A., Pino-Benítez, I., AlbaVallejo, M., Moreno-Küstner, B. and Mayoral-Cleries, F. (2016) Effectiveness of a multimodal intervention program for restraint prevention in an acute Spanish psychiatric ward. Journal of the American Psychiatric Nurses Association, 22(3), 233-241.

Health Foundation (2017) In short supply: pay policy and nurse numbers - Nurse staffing: can the new guidelines make a difference? The Health Foundation, London.

Huckshorn, K. A. (2006) Re-designing state mental health policy to prevent the use of seclusion and restraint. Administration and Policy in Mental Health and Mental Health Services Research, 33(4), 482-491. 
Imison C (2016) Can we solve the nursing workforce crisis? Nuffield Trust comment, 21 November 2016. https://www.nuffieldtrust.org.uk/news-item/can-we-solve-the-nursingworkforce-crisis. (accessed 8 September 2018).

International Council of Nurses (2014) Safe staffing saves lives.

http://www.icn.ch/publications/2006-safe-staffing-saves-lives/ Published 2006. Updated April 3, 2014. (accessed 8 September 2018).

International Labour Organization. (2005) ILO nursing personnel convention no. 149. International Labour Office, Geneva.

ILO/ICN/WHO/PSI (2002) Framework guidelines for addressing workplace violence in the health sector. ILO/ICN/WHO/PSI Joint Programme on Workplace Violence in the Health Sector, Geneva.

Jenkins, R. and Elliott, P. (2004) Stressors, burnout and social support: nurses in acute mental health settings. Journal of Advanced Nursing, 48(6), 622-631.

Jones, A. and Gregory, S. (2017) Is collecting care hours per patient day the way forward in determining safe staffing for inpatient mental health wards? Journal of Psychiatric and Mental Health Nursing, 24(2-3), 178-181. 
Kieft, R.A., de Brouwer, B.B., Francke, A.L. and Delnoij, D.M. (2014) How nurses and their work environment affect patient experiences of the quality of care: a qualitative study. BMC Health Services Research, 14(1), 249.

LeBel J, Stromberg N, Duckworth K, et al. (2004) Child and adolescent inpatient restraint reduction: a state initiative to promote strength-based care. Journal of the American Academy of Child and Adolescent Psychiatry, 43:37-45.

Lewis, M., Taylor, K. and Parks, J. (2009) Crisis prevention management: a program to reduce the use of seclusion and restraint in an inpatient mental health setting. Issues in Mental Health Nursing, 30:159-164.

Liegghio, M. (2013) A denial of being: psychiatrization as epistemic violence. In B. Lefrancois, R. Menzies, \& G. Reaume (Eds.), Mad matters: A critical reader in Canadian mad studies (pp. 122-129). Canadian Scholars Press, Toronto.

Littlejohns, P. (2015) Basing safe staffing levels on evidence. British Medical Journal, 351, h4556.

Looi, G.M.E., Engström, Å. and Sävenstedt, S. (2015) A self-destructive care: Self-reports of people who experienced coercive measures and their suggestions for alternatives. Issues in Mental Health Nursing, 36(2), 96-103. 
Macintyre, A., Ferris, D., Gonçalves, B. \& Quinn, N. (2018) What has economics got to do with it? The impact of socioeconomic factors on mental health and the case for collective action. Palgrave Communications, 4(10) DOI: 10.1057/s41599-018-0063-2

Masters, K.J. (2018) Seclusion and restraint: the voice of the patient. The Canadian Journal of Psychiatry, 63(2), 78-79.

MIND (2013) Mental health crisis care: physical restraint in crisis. A report on physical restraint in hospital settings in England. MIND, London.

McEvoy, P. \& Richards, D. (2003). Critical realism: A way forward for evaluation research in nursing? Journal of Advanced Nursing, 43, 411-420.

McKeown, M., Edgar, F., Spandler, H. and Carey, L. (2018) Conscientization and Transformation in the Workplace: New Forms of Democracy for Mental Health Services. In A. Melling \& R. Pilkington (eds) Paulo Freire and Transformative Education (pp. 153-163). Palgrave Macmillan, London.

McKeown, M. \& Foley, P. (2015) Reducing physical restraint: an employment relations perspective. Journal of Mental Health Nursing, 35, 1, 12-15.

McKeown, M., Scholes, A., Jones, F. and Aindow, W. (2019) Coercive practices in mental health services: stories of recalcitrance, resistance and legitimation. in A. Daley, L. Costa and P. Beresford (Eds) Madness, violence and power. University of Toronto Press, Toronto. 
McKeown, M. and White, J. (2015) The future of mental health nursing: are we barking up the wrong tree? Journal of Psychiatric and Mental Health Nursing, 22(9), 724-730.

McKeown, M., Wright, K. and Mercer, D. (2017) Care planning: a neoliberal three card trick. Journal of Psychiatric and Mental Health Nursing, 24(6), 451-460.

Mistry, H., Levack, W.M. and Johnson, S. (2015) Enabling people, not completing tasks: patient perspectives on relationships and staff morale in mental health wards in England. BMC Psychiatry, 15, 307. doi.org/10.1186/s12888-015-0690-8

Muir-Cochrane, E. (2018) On restrictive practices: care and culture. Journal of Psychiatric and Mental Health Nursing, doi.org/10.1111/jpm.12492

National Audit Office (2016) Managing the supply of NHS clinical staff in England. NAO, London.

O'Connor, K., Neff, D.M. and Pitman, S. (2018) Burnout in mental health professionals: A systematic review and meta-analysis of prevalence and determinants. European Psychiatry, $53,74-99$.

Pereira, S., Dawson, P. \& Sarsam, M. (2006) The National Survey of PICU and low secure services: 2. Unit characteristics. Journal of Psychiatric Intensive Care, 2, 3-19. 
Perkins, E., Prosser, H., Riley, D., \& Whittington, R. (2012) Physical restraint in a therapeutic setting; a necessary evil? International Journal of Law and Psychiatry, 35(1), 43-49.

Price, O. \& Baker, J. (2012) Key components of de-escalation techniques: A thematic synthesis. International Journal of Mental Health Nursing, 21(4), 310-319.

Putkonen, A., Kuivalainen, S., Louheranta, O., Repo-Tiihonen, E., Ryynänen, O.P., Kautiainen, H. and Tiihonen, J. (2013) Cluster-randomized controlled trial of reducing seclusion and restraint in secured care of men with schizophrenia. Psychiatric Services, 64(9), 850-855.

Quirk, A. and Lelliott, P. (2001) What do we know about life on acute psychiatric wards in the UK? A review of the research evidence. Social Science \& Medicine, 53(12), 1565-1574.

Randall, D. \& McKeown, M. (2014) Failure to care: nursing in a state of liquid modernity? Journal of Clinical Nursing, 23, 766-767.

RCN (Royal College of Nursing) (2014). Frontline first: turning back the clock? RCN report on mental health services in the UK.

www.rcn.org.uk/ data/assets/pdf file/0004/600628/004772.pdf (accessed 8 September 2018). 
Reid, Y., Johnson, S., Morant, N., Kuipers, E., Szmukler, G., Thornicroft, G., Bebbington, P. and Prosser, D. (1999) Explanations for stress and satisfaction in mental health professionals: a qualitative study. Social Psychiatry and Psychiatric Epidemiology, 34(6), 301-308.

Riahi, S., Thomson, G. and Duxbury, J. (2016) An integrative review exploring decisionmaking factors influencing mental health nurses in the use of restraint. Journal of Psychiatric and Mental Health Nursing, 23(2), 116-128.

Roberts, M. \& Ion, R. (2014) A critical consideration of systemic moral catastrophe in modern health care systems: a big idea from an Arendtian perspective. Nurse Education Today, 34(5), 673-675.

Sharac, J., McCrone, P., Sabes-Figuera, R., Csipke, E., Wood, A. \& Wykes, T. (2010) Nurse and patient activities and interaction on psychiatric inpatients wards: a literature review. International Journal of Nursing Studies, 47(7), 909-917.

Spetz, J. (2004) California's minimum nurse-to-patient ratios: the first few months. Journal of Nursing Administration, 34, 571-8.

Stuckler, D., Reeves, A., Loopstra, R., Karanikolos, M. \& McKee, M. (2018) Austerity and health: the impact of crisis in the UK and the rest of Europe. In M. Castells et al. (Eds) Europe's crises. (pp.127-147). Polity Press, Cambridge Cambridge. 
Sweeney, A., Filson, B., Kennedy, A., Collinson, L. and Gillard, S. (2018) A paradigm shift: relationships in trauma-informed mental health services. Bjpsych Advances, 24(5), 319-333.

Szmukler, G., \& Appelbaum, P. S. (2008). Treatment pressures, leverage, coercion, and compulsion in mental health care. Journal of Mental Health, 17(3), 233-244.

Taylor, B. and Barling, J. (2004) Identifying sources and effects of carer fatigue and burnout for mental health nurses: a qualitative approach. International Journal of Mental Health Nursing, 13(2), 117-125.

ten Hoeve, Y., Jansen, G. and Roodbol, P. (2014) The nursing profession: public image, self-concept and professional identity. A discussion paper. Journal of Advanced Nursing, 70(2), 295-309.

Thomas, P. (2016) Psycho politics, neoliberal governmentality and austerity. Self \& Society, 44(4), 382-393.

Unison (2017) Ratios not rationing. https://view.officeapps.live.com/op/view.aspx?src=https\%3A\%2F\%2Fwww.unison.org.uk\%2 Fcontent\%2Fuploads\%2F2017\%2F04\%2FRatiosNotRationing.docx (accessed 13 February 2019). 
Unison (2019) Just another day: 24 hours in the NHS - compromised care, staff shortages and serious stress. https://www.unison.org.uk/content/uploads/2019/01/Just-Another-Day.pdf (accessed 13 February 2019) 